\title{
OS (DES)CAMINHOS DE UMA HISTÓRIA DA IMIGRAÇÃO JUDIA
}

\section{THE UNUSUAL PATH OF A HISTORY OF JEWISH IMMIGRATION}

\author{
Tissiano da Silveira*
}

SCHPUN, Mônica Raisa. Justa. Aracy de Carvalho e o resgate de Judeus: trocando a Alemanha nazista pelo Brasil. Civilização Brasileira: Rio de Janeiro, 2011. $530 \mathrm{p}$.

Ao iniciarmos a leitura do livro de Mônica Raisa Schpun logo vemos que não é apenas uma obra sobre a perseguição aos judeus, apesar do título, outras questões são discutidas, como as estratégias utilizadas por eles para se adaptar às mudanças que os segregavam, dificultavam sua permanência na Alemanha e os levavam para os caminhos da emigração, caminhos estes descritos com enorme sensibilidade por Schpun. O texto transcorre a partir da trajetória de duas mulheres que, em seus deslocamentos, se cruzam e iniciam uma amizade ímpar, que duraria muitos anos desde a primeira vez que se conheceram no consulado brasileiro em Hamburgo. Nestes transcursos a autora lança um olhar para os entraves da burocracia imigratória brasileira que dificultava a vinda de judeus, com políticas veladas que se alinhavam com a de outros países que não desejavam este povo em seus territórios.

Uma destas mulheres retratadas por Schpun era Aracy de Carvalho, principalmente no período que esta ocupa um posto no consulado brasileiro em Hamburgo, a outra era Margarethe Levy, que no mesmo momento, tentava sair de uma Alemanha hostil para ela e seu marido. As duas tornam-se nossas guias pelos tortuosos caminhos de uma parte da imigração judia com destino ao Brasil.

\footnotetext{
* Doutorando no Programa de Pós-Graduação em História da Universidade Federal de Santa Catarina (UFSC) e bolsista do CNPq. E-mail: tissiano.silveira@gmail.com
} 
Não fosse esta situação, quais as chances deste encontro? Aracy, uma brasileira, católica, deixara para trás seu país, uma vida típica de classe média, um casamento, elementos muito comuns às jovens paulistanas na década de 1930. Quando partiu, tinha somente 26 anos e carregava consigo Eduardo então com cinco anos. Enquanto isto, na Alemanha, provavelmente Margarethe, também com 26 anos, gozava a vida de uma família abastada, até os 12 anos teria vivido em hotéis de luxo, principalmente na Suíça, viajava pela Europa - muitas vezes sozinha -, portanto, além de sua língua materna, falava inglês, francês e italiano, vindo morar no Brasil acabou por aprender mais um idioma.

Mas o encontro um tanto improvável aconteceu num momento em que Aracy tinha as condições necessárias para ajudar Margarethe em sua frágil situação, aliás fragilidade não é a palavra adequada para estar associada ao povo judeu, mas dá conta de um momento em que a formação, a cultura e mesmo o dinheiro não eram suficientes para manter o status das famílias judias na Alemanha.

Este é portanto um livro sobre imigração, porém a autora faz mais do que nos levar aos trânsitos e barreiras das viagens, ao discutir questões racistas e também ao falar da situação das mulheres judias no período, mostrando a complexidade da sociedade alemã. Pois, mesmo com as medidas cada vez mais duras do governo, os cidadãos alemães continuavam a conviver com vizinhos judeus, dentistas e médicos judeus, donos de comércios judeus, e assim se relacionavam de diferentes formas com eles, possibilitando que muitos judeus pudessem ter mantido por algum tempo suas atividades e se organizassem para deixar o país antes das prisões e violência generalizada que se prenunciava.

É claro que os judeus não foram, de um dia para o outro, apartados da sociedade, afinal eles também faziam parte dela, os processos foram pouco a pouco isolando a comunidade judaica, pelo menos antes da noite de cristal a série de eventos violentos da noite de 9 de novembro de 1938 que acirrou a animosidade contra os judeus a partir de então. Perdia-se direitos e as animosidades cresciam de forma desigual no país, apesar de Hamburgo não ser propriamente uma cidade pequena no período descrito por Schpun. Ela mostra diversas situações que revelam as estratégias e as redes de relações que prolongam um certo ar de normalidade, principalmente para os não judeus, a autora descreve um cartão que Aracy envia para sua mãe em que demonstra os ares de felicidade que tomavam conta das cidades alemãs durante os jogos olímpicos.

Schpun deixa claro que este livro não é uma biografia, apesar da tentação que deve ser a de contar a vida de uma pessoa importante para a comunidade judaica e que foi casada com o escritor João Guimarães Rosa, mas ela mantém o caráter historiográfico da obra, influenciada por suas pesquisas acadêmicas sobre imigração. Monica Schpun é bacharel em História pela Universidade de São Paulo (1986), com doutorado em História pela Université de Paris VII 
(1994), é pesquisadora na École des Hautes Etudes en Sciences Sociales de Paris, Centre de Recherches sur le Brésil Contemporain, atuando principalmente nos temas migração, gênero e São Paulo da década de 1920.

Acredito que algumas escolhas editoriais devem ter influenciado o livro, não é raro encontrá-lo resenhado (em resenhas literárias) como sendo uma biografia, o que não é um problema, mesmo porque a escolha por trajetórias foi uma boa solução para que a leitura se tornasse de fácil acesso para leitores que não são historiadores. Assim se colocando num mercado que cresce cada vez mais, o livro deve agradar aqueles que querem informação sobre migração tanto quanto àqueles que desejam saber da vida de Aracy de Carvalho.

Os deslocamentos dão o tom da primeira parte do livro, primeiro de uma brasileira separada e com um filho pequeno que procura a Alemanha para recomeçar a vida e o de uma judia abastada que vê sua vida ser radicalmente modificada pelas políticas raciais do III Reich, e portanto, tendo que rapidamente imigrar para o Brasil. Isto nos leva a uma série de questões discutidas pela autora, desde a situação de uma mulher separada na década de 1930, como a de mulheres judias que nunca tinham trabalhado mas que se viam na situação de empregadas domésticas, já que eram menos perseguidas que os homens, tendo maior mobilidade, podiam ir às ruas com maior segurança, assim podendo ir às lojas e ir ao trabalho, invertendo a situação comum dos provedores da casa.

Aracy em seu posto no consulado se tornou uma peça chave para que muitos judeus conseguissem a permissão para imigrar, inclusive Margarethe Levy, e por isto se tornou pessoa importante para a comunidade judaica, o título do livro se refere a uma honraria que ela recebeu em 1982, o título "Justa entre as Nações" concedido pelo Museu do Holocausto de Jerusalém.

As políticas brasileiras e alemãs quanto a imigração, são mostradas por Mônica Schpun quando esta relata os diversos casos que estavam assinalados nas cadernetas pessoais de Aracy, as quais a autora teve acesso e que se mostraram muito interessantes para fazer a conexão entre relatos e documentos levantados por ela. As cartas trocadas por Aracy, principalmente com sua mãe, também são fontes preciosas, nelas o tom informal de conversas entre pessoas tão íntimas revelam as angustias e rotinas de Aracy, alguns detalhes das cartas se tornaram rastros para que a autora refizesse histórias de famílias que foram ajudadas por Aracy. Mônica Schpun se utiliza várias vezes desse artifício, procurando em lugares incomuns os indícios que podem desvelar tramas num momento histórico tão conturbado, principalmente para a comunidade judia.

Aliás, a maneira de construir suas fontes é muito interessante, Schpun coloca uma lente de aumento nos casos particulares, para retratar toda uma sociedade que tinha que lidar com as vicissitudes da época: de um lado os judeus que sentiam na pele as políticas governamentais que estimulavam o racismo contra eles e de outro os alemães que tinham que se afastar daqueles judeus com os quais tinham algum tipo de relação - as mulheres que eram 
casadas com judeus eram cada vez mais discriminadas - assim levando muitos judeus a deixar o país.

A autora também está preocupada em perceber as fissuras e, através delas, pensar outras questões, dessa maneira Schpun vai falar das pequenas redes de solidariedade que se constroem abaixo das políticas oficiais e que envolvem não só judeus. A situação das mulheres judias perpassa vários momentos do livro, sendo este um assunto que faz parte dos estudos da autora, as questões de gênero. Num contexto de violência, engendram-se estratégias de mulheres que não tinham o trabalho fora de casa como rotina mas que conseguem dar suporte à suas famílias quando a presença homens com tipo físico que demonstrassem sua origem judaica era menos suportado nas ruas do que a delas.

O livro também demarca uma posição política na história, entrando no rol daqueles que nos fazem não esquecer o horror da perseguição e extermínio de judeus e outros povos durante o nazismo. Mas diferente das obras clássicas como "É isto um homem?", de Primo Levi, que descrevem os campos de concentração, um período crítico e de muitas mortes, o livro de Schpun descreve um período anterior aos pogrons - ataques violentos em massa - e as deportações para campos de prisioneiros, um momento em que ainda era possível emigrar, apesar das dificuldades burocráticas que se tornavam cada vez mais problemáticas.

Neste sentido o livro faz uma crítica ao Estado brasileiro, com políticas que criavam vários entraves a imigração. Porém, acredito que sua abordagem é diferente da obra de Maria Luiza Tucci Carneiro sobre o antissemitismo na Era Vargas, pois ela é mais branda quanto uma posição antissemita por parte do governo. Apesar de demonstrar que vários burocratas atuavam de forma a dificultar a imigração de judeus, não parece ser esta uma postura institucional, ainda mais que os documentos que norteavam a diplomacia brasileira em grande parte eram circulares secretas que demonstravam muito mais uma grande indiferença pela situação dos judeus na Alemanha nessa época

Apesar de Schpun ressaltar que este não é um livro biográfico, não é problema que seja visto como tal. Mostrar as decisões pessoais de Aracy, que viriam a salvar inúmeras vidas, para mim foi um ponto positivo do livro, pois ter coragem para utilizar sua posição estratégica no Consulado, tem muito das outras decisões que ele tomou em sua vida, sua coragem em se separar do marido com um filho ainda pequeno, mudar de país para reconstruir a vida e até mesmo sua decisão de aprender a dirigir e comprar um carro, tudo isto diz muito de seu temperamento e portanto faz parte de um conjunto de momentos de sua trajetória pessoal que acho fundamental para entender sua atitude humanitária.

A autora conseguiu escrever história com uma leveza que contrasta com a temática abordada, porém, se aprofundando em questões muito interessantes que atravessam a história da imigração judaica. Entender os recursos e 
estratégias usadas pelos judeus para deixarem a Alemanha e se restabelecerem num outro país, se torna tão interessante quanto saber das políticas alemãs que os forçaram a tal atitude.

A História que tentava dar um sentido para os acontecimentos não faz sentido nos nossos dias, ao contrário, a disciplina cada vez mais traz à tona questões que não estão necessariamente fechadas, conclusas, mas que podem instigar, que nos dizem algo aos dias atuais. E isto é feito por Mônica Schpun, quando resolveu trilhar novos caminhos para fazer uma história das imigrações, passando pelas pessoas, por suas motivações, sonhos e frustrações, por suas histórias, afinal.

Resenha recebida em agosto de 2013. Aceita em agosto de 2013. 